\title{
Pathogenic Variability and Differential Interaction of Blast Fungus (Pyricularia grisea SACC.) Isolates with Finger Millet Lines in Nepal
}

\author{
R.B. Khadka ${ }^{3}$, S.M. Shrestha ${ }^{1}$, H.K.Manandhar ${ }^{2}$ and G.B. K.C. ${ }^{1}$ \\ ${ }^{1}$ Institute of Agriculture and Animal Sciences (IAAS), Rampur, Chitwan \\ ${ }^{2}$ Nepal Agricultural Research Council (NARC), Singhadurbar plaza, Kathmandu \\ ${ }^{3}$ Regional Agricultural Research Station, Khajura, Banke \\ e-mail: vijayautsarga@gmail.com
}

\begin{abstract}
To understand the pathogenic variability of Nepalese isolates of Pyricularia grisea pathogenic to finger millet and their differential interaction with this millet exotic lines and landraces, an experiment was conducted at Institute of Agriculture and Animal Sciences (IAAS), Rampur, Chitwan during August to October, 2008. Five Pyricularia isolates collected from Lumle, Pokhara, Gulmi, Kabre and Rampur were tested with five landraces Acc\#4337, Acc\#6202, Acc\#456, KLB\#184, Kabre and four exotic lines, PR\#202, HR\#911, SPFM\#K2, and GPU\#48 which have been used in national finger millet research programme by Hill Crop Research Programme (HCRP), Kabre, Dolakha. The experiment was laid out in 5x 9 factorial completely randomized designs with 4 replications in screen house. Eighteen-day-old seedlings grown in earthen pots were inoculated with a Pyricularia spore suspension $\left(10^{5} \mathrm{ml}^{-1}\right)$ with the hand sprayer. Disease assessment was done in five days after inoculation. The aggressiveness of the isolates was noticed maximum in Pokhara and minimum in Gulmi isolates. Considerable pathogenic variations among the tested isolates were observed, however, no clear cut differential interactions were noticed in the interaction. The exotic lines showed comparatively resistant against the fungus reaction than the landraces. Among the tested lines Gpu\#48, showed resistant reaction and Acc\#4337 showed susceptible reaction in artificial inoculation.
\end{abstract}

Key words: inoculation, virulence, aggressiveness, susceptibility, resistant reaction

\section{Introduction}

Finger millet is the fourth important cereal crop after rice, maize and wheat in Nepal which cover 265,160 ha land with 284,813 mt. production and $1074 \mathrm{~kg} / \mathrm{ha}$ productivity in Nepal (HCRP 2007). It occupies almost $9 \%$ of the total cultivated area in the country and $76 \%$ cultivation area lies in mid-hills (HCRP 2007). The importance of the crop is more in subsistence farming system where it is grown without external input in marginal land and provides a sustaining diet for rural people. Finger millet is very hardy annual crop, tolerant to drought and is the primary food source for millions of people in tropical dry land regions (CGIAR 2007). Blast, caused by Pyricularia grisea, is the major production constraint of finger millet (ICRISAT 2007). Ghimire and Pradhanag 1994 reported severe effect by blast, $70-90 \%$ in nursery bed, $60 \%$ neck blast and
3-80\% finger blast at Lumle, Kaski. It is the most destructive disease for yield and biomass reduction in Nepal (Subedi \& Budha 1996). Recently up to $40 \%$ neck blast and $25 \%$ finger blast has been reported in the farmer's field of hill of areas (Prasad 2008).

The disease damages the foliage, neck and finger in different growth stages of the finger millet. Infection prior to milking stage induces the finger sterility and reduces the grain weight and number whereas the infection after milking stage attributes to the reduction in seed size, number and 1000 seed weight (Hunsigi \& Krishna 1998, NARC 1997).

Blast fungus can be successfully controlled through some fungicidal sprays (HCRP 2003) but management through chemical agents leads to the establishment of 
resistant strains to these chemicals. Moreover, when these chemicals are used indiscriminately, they also pose a serious threat to the environment (Karthikeyan \& Gnanamanickam 2007).

Host resistance is the highly cost effective, safe convenient and preferable means of plant protection. The use of resistant cultivars is the most desirable method of managing blast disease in finger millet. Resistant cultivars cost the farmer nothing, pose no pollution and are readily adopted (Barman 1990). Host resistance, even being a preferred tactic for blast management, sometimes it fails due to evolutionary changes in the pathogen population. Previously resistant cultivars may become ineffective and suddenly and catastrophically susceptible. Zieglier et al. (1997) and Ziegler (1998) reported parasexual recombination is also a mean of variation. Potential role of sexual recombination in the structure of $P$. grisea population has also been substantiated in the Indian Himalayas (Kumar et al. 1999).

Both phenotypic and genotypic variability in Pyricularia has been described by many workers. Among them the major base of pathogenic variability is the host specificity. The molecular genetic studies demonstrate that $P$. grisea is composed of groups of isolates that are genetically diverse (Levy et. al. 1991, 1993).Similarly Ou 1979 stated that variation in the pathogen is due to the heterokaryosis or by variation in chromosome numbers or due to chromosome anomalies (Glatgong \& Fredereksen 1969) or genomic rearrangements. Zieglier et al. 1997 and Ziegler 1998 reported parasexual recombination is also a mean of variation. Potential role of sexual recombination in the structure of $P$. grisea population has also been substantiated in the Indian Himalayas (Kumar et. al. 1999). Pathogenic variability in Pyricularia isolates of finger millet is also supported by the finding of Kato 1978. He noticed the physiological heterothallism in finger millet isolates with at least two different compatibility types A, and a which were reported in Japan, Nepal, India and Uganda.

Studies on the virulence of finger millet blast pathogen populations have led to the investigations on genetics of host resistance. This may result in the selection of differential finger millet varieties for identifying the races of $P$. grisea. There is no information available for any attempt made to develop a tentative set of differentials for assessing the racial differentiation among finger millet blast pathogen population. However, in case of rice crop, so many site specific and international sets of differentials have been developed (Atkins et al. 1967, Ling \& Ou 1969, Ou 1972, Bonman et al. 1986). It is essential to utilize the knowledge of the pathogen, host and environment interaction to develop stable and durable resistance and also to monitor the long-term genetic interaction (Sreenivasaprasad et.al. 2004).

The research mainly focused the variability of the blast fungus in finger millet among different climatic and geographical belts of Nepal. It identifies the differential interaction of fungal isolates with promising finger millet lines used in the national finger millet research programme. Similarly it has expected to identify the virulence spectra of the fungal isolates which will be helpful to identify the location which is most suitable for screening finger millet lines for blast. The differential interaction with mono-conidial culture of Pyricularia isolates have expected to identify the differential sets of finger millet.

\section{Methodology}

The experiment was conducted at IAAS, Rampur, Chitwan, during August to October, 2008. Five isolates of $P$. grisea were collected from different locations of the country. Ten promising finger millet lines used in the national finger millet research programme (NFMRP) were selected.

Soil was sterilized by $4 \%$ formalin solution at the rate of $7 \mathrm{lt} / \mathrm{m}^{3}$. Sterilized earthen pots $(20 \mathrm{~cm}$ dia. $\times 15 \mathrm{~cm}$ depth) were filled with $5 \mathrm{~kg}$ sterilized dry soil. The finger millet seeds were sown following the dibbling methods in each pot. The soil was fertilized with NPK @0.4:0.15:0.1 g/ kg soil and FYM @ 10 ton/ha. 10-15 seeds of each selected accession were sown at 1-1.5 $\mathrm{cm}$ apart and were covered with thin layer of soil.

The blast infected leaf samples were cut from the plant and kept into brown paper envelops. They were taken in to the laboratory and subjected to the process of isolation.

\section{Isolation of $P$. grisea}

To isolate the pathogens the infected parts of the collected leaves were cut in to small pieces (about $2 \mathrm{~mm}$ ) with scissors. The pieces were surface sterilized 
R. B. Khadka et al./Pathogenic Variability and Differential .....

with $1 \%$ sodium hypochloride for 1 minute, followed by two successive cleaning with distilled water. Then they were put in clean sterile petridished containing three layers of moistened blotting paper. The samples were then incubated at 25 to $26^{\circ} \mathrm{C}$ for 24 hours. From the sporulating lesions, single spores were transferred to separate culture tubes of prune agar slants. Single spore isolates were obtained by spreading conidia from the discrete lesions on $4 \%$ water agar (AGAR-AGAR, Qualigens, Fine Chemicals, Mumbai, India) with the help of inoculating needle under stereomicroscope. Germinating conidia were transferred aseptically to Prune agar plate one by one. The plate was incubated in an incubator at $25 \pm 2{ }^{\circ} \mathrm{C}$ for 3- 4 days.

Table1. Locations of collected disease samples and varieties

\begin{tabular}{llllll}
\hline SN & Location & District & Representing environment & Variety & Elevation \\
\hline 1 & Lumle & Kaski & Mid hill (Mid region) $(1400 \mathrm{msl})$ & Local & $1400 \mathrm{msl}$ \\
2 & Matepani & Kaski & Mid hills valley (900msl) & Dalle & $900 \mathrm{msl}$ \\
3 & Rampur & Chitwan & Terai and inner Terai $(256 \mathrm{msl})$ & Local & $256 \mathrm{msl}$ \\
4 & Kabhre & Dolakha & Mid hill (Eastern region) $(1740 \mathrm{msl})$ & Kabre kodo-1 & $1740 \mathrm{msl}$ \\
5 & Bastu & Gulmi & Mid hill (Western region) $(950 \mathrm{msl})$ & Local & $950 \mathrm{msl}$ \\
\hline
\end{tabular}

\section{Mass production of fungal spores}

For mass production of the fungal spores, 5 fungal blocks of $5 \mathrm{~mm}$ diameter were cut from the pure culture and placed in direct contact with medium of each prune agar plate. Then the plates were made air tight with parafilm sheet and kept for incubation for 3-4 days at $25^{\circ} \mathrm{C}$. When the surface of the medium was fully covered with fungal mycelium, it was scrapped with sterilized glass slides by adding 5-10 $\mathrm{ml}$ sterilized distilled water. The sterilized plates with fungal suspension were exposed to continuous fluorescent light for 20-25 days.

\section{Inoculum preparation}

The culture plates were then flooded with sterile distilled water and allowed to stand for 5 minutes. Then they were scrapped with sterile glass rod to dislodge the spores. The spore suspension was filtered through double layer of muslin cloth and the concentration of the spore suspension was estimated using a Reichert Brite-line haemocytometer. Spore suspension was then diluted to the required concentration with sterile distilled water.

\section{Experimental design}

The treatments were allocated in factorial complete randomized design CRD (9x5) with four replications in screen house of IAAS, Rampur, Chitwan. Five fungal isolates collected from five geographically different locations (Lumle, Pokhara, Chitwan, Dolakha and Gulmi) were taken as a factor " $\mathrm{a}$ " and nine finger millet genotypes (ACC4337, ACC6202,
HR911, Kabre, SPFMK2, ACC456, PR202, KLB184 and GPU48) were taken as a factor "b". Each isolate were artificially inoculated with each genotypes separately.

\section{Foliar inoculation}

Each variety of the finger millets with four replications were kept in separate iron cages and separated by plastic sheet, so as to protect the cross inoculation of fungal spore from one cage to another due to air drift. Each pot was provided with sufficient water before inoculation. Eighteen-day- old seedlings were inoculated with a spore suspension $\left(10^{5} \mathrm{ml}^{-1)}\right.$ with the hand sprayer at late afternoon. The seedlings were then covered with a wet jute bag for 48 hours. Relative humidity, above $90 \%$ was maintained by spraying water through hand sprayer and wetting the jute bag watering with rose can at 2 hours interval. After 48 hours, the jute bags were removed and the plants were covered with white transparent polythene sheet, keeping covered during day and open at night time until scoring.

\section{Observation}

Relative humidity and temperature of the iron cage at 12 hours interval from the times of inoculation were recorded. Five days after inoculation, the disease scoring was done in a 0-9 scale by randomly taking 5 plants from each pot. The disease scoring was done in for four upper leaves of each plant and disease intensity was graded on 0-9 scale, where 0 indicates maximum resistance and 9 indicates maximum susceptibility resulting in seedling death (Latha et al. 2005). Disease severity was calculated by the following formula (Shrestha \& Mishra 1994). 
Disease intensity and severity \% =

$$
\begin{aligned}
& \text { Sum of the rumerical ratings } \\
& \text { Total nunber of leaves or plants observed } \times \text { Maximumating } \times 100
\end{aligned}
$$

\section{Results and Discussion}

\section{Green house experiment}

Aggressiveness of Pyricularia grisea isolates collected from different location

Differential aggressiveness of the tested fungal isolates was observed in planted finger millets genotypes in green house. Among the different isolates tested in green house to determine the aggressiveness of the isolates, it has been shown that the isolates collected from Pokhara had maximum aggressiveness followed by Kabre and the isolates from Gulmi had lowest aggressiveness. There was significant difference in average disease incidence caused by all five isolates in all finger millet lines. Maximum disease incidence was obtained in isolates from Pokhara i.e. 34.56 and which was significantly higher than the other isolates and similarly minimum disease incidence was obtained in Gulmi isolates, which was also significantly different from other isolates (Fig. 1).

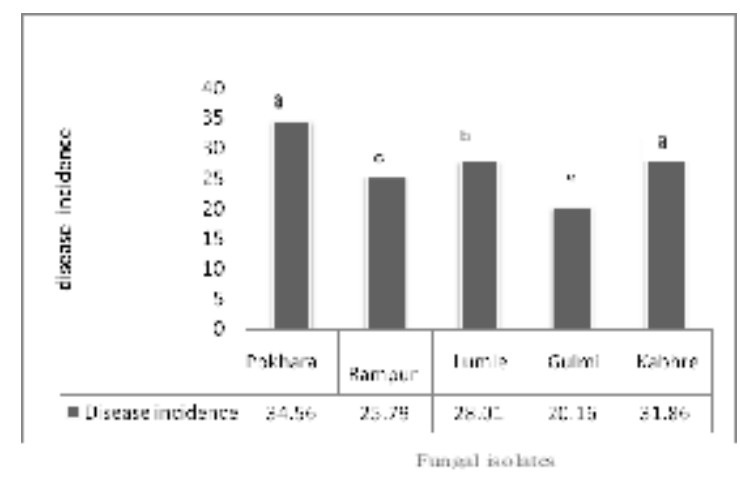

Fig. 1. Disease severity of 5 Pyricularia grisea isolates collected from five locations in nine Finger millet genotypes in a green house at, Rampur, Chitwan during August to October,2008
The origin of geographical regularity has close relation to the deficiency or specificity of relevant resistance gene(s). No identical reaction patterns were observed among cultivars, indicating their highly distinctive isolate specificity. The virulence of isolates were obtained significantly diverse, in the location from where isolates were collected. Geographical isolation and specificity regulate the genetic makeup of the organism. Same pattern of aggressiveness in different host-blast interaction has been studied in Setaria (Nakayama et. al. 2005), rice (Roumen, 1992, Mekwatanakarn et al. 2000), finger millet (Conroy et al. 1999).

Highest aggressiveness in isolates from Pokhara and Kabre among the tested lines show higher diversity of the blast population at Pokhara and Kabre might be due to the diversity of finger millet cultivated over the years as host genotype is known to influence the composition of the pathogen population. The result is supported by Chen et al. 1995, Park et al. 2003 in case of rice blast population. Such diversity indicates that Pokhara and Kabre are better screening sites for durable resistance than the rest of the locations. Conroy et al. (1999) reported considerable variation in the aggressiveness of $M$. grisea isolates on the seedlings of the ten finger millet varieties tested in East Africa. He further reported most aggressive isolates; in general they were aggressive on all ten varieties tested and, similarly, the least aggressive isolates produced low levels of disease on all the varieties. This aggressive response was also characteristic of several other pathogen race-cultivar combinations (Akai 1939, Kahn \& Libby 1958, Koh et al. 1987, Roumen 1992).

\section{Susceptible and resistance reaction of finger millet lines in greenhouse test}

In green house test different assessments were used to determine the resistance of the finger millet varieties. The disease incidence was obtained maximum in ACC\#4337(42.04) and minimum in GPU48 (11.52) followed by SPFMK2 (13.8) which were significantly different (Fig. 2). 


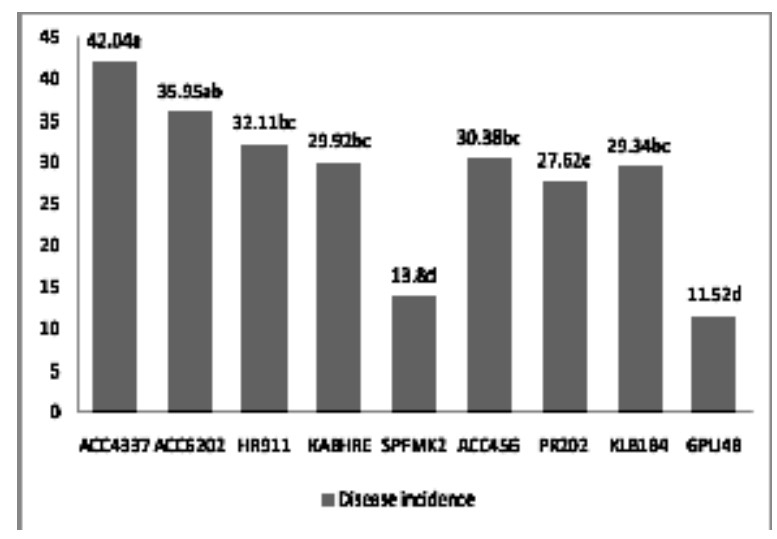

Fig. 2. Leaf blast severity in nine finger millet genotypes under artificial inoculation with Pyricularia grisea isolates in green house at Rampur during August to October, 2008

The exotic varieties showed comparatively resistance with leaf blast than the landraces. Gpu\#48, Spfm\#k2 and HR\#911 showed resistance reaction. These could be selected for further research to release as blast resistant varieties and donor in Nepal. Maximum disease severity was found in Acc\#4337. So this variety could be used as a susceptible check and blast trapper line in leaf blast research. GPU\#48 was reported to be the most resistant and ACC\#4337 as the most susceptible genotype. Hence both of these genotypes could be recommended as check genotypes in finger millet blast screening programme in Nepal.
Sreenivasaprasad et al. 2001 reported leaf blast severity ranging from 35.1 to 91.35 in East Africa. They noticed leaf blast score range 2-6 (mean 3.4) with a severity range of 16.8-57.3 (mean 33.2) in tested varieties. They also found variation in leaf blast incidence in the same varieties in different locations. Results of the study of Sreenivasaprasad et al. (2001) also clearly revealed that among all the genotypes studied, no lines showed immune response to leaf blast severity.

\section{Differential interaction of finger millet lines with different isolates of $P$. gresia.}

Some differential reactions were noticed among the lines to a particular blast isolate in green house experiment. Most aggressive isolates (Pokhara) could produce susceptible reaction in maximum genotypes (3 genotypes) where as least aggressive isolates (Gulmi) could produce susceptible reaction only in HR\#911. Isolates from Pokhara developed susceptible reaction in ACC\#4337, ACC\#6202, HR\#911; moderately resistance reaction in PR\#202 and resistance reaction in Kabre, ACC\#456, KLB\#184, GPU\#48, whereas isolates from Rampur developed some contrast results. It caused susceptible reaction only in Acc\#6202. Many of the lines showed resistance with this isolates i.e. HR\#911,Kabhre, SPFM\#K2, ACC\#456, KLB\#184, GPU\#48 and only two genotypes showed a moderately susceptible reaction i.e. PR\#202, ACC\#4337 (Table 2).

Table 2. Differential interaction of selected finger millet lines with five different isolates in screen house, Rampur, Chitwan, 2008

\begin{tabular}{l|l|l|l|l|l|l|l|l|l}
\hline IsolatelLinest & ACC4337 & ACC6202 & HR911 & KABRE & SPFMK2 & ACC456 & PR202 & KLB184 & GPU48 \\
\hline $\mathrm{Pi}$ & $\mathrm{S}$ & $\mathrm{S}$ & $\mathrm{S}$ & $\mathrm{R}$ & $\mathrm{R}$ & $\mathrm{R}$ & $\mathrm{MR}$ & $\mathrm{R}$ & \\
$\mathrm{Ri}$ & $\mathrm{MR}$ & $\mathrm{S}$ & $\mathrm{R}$ & $\mathrm{R}$ & $\mathrm{R}$ & $\mathrm{R}$ & $\mathrm{MR}$ & $\mathrm{R}$ & $\mathrm{R}$ \\
$\mathrm{Li}$ & $\mathrm{R}$ & $\mathrm{MR}$ & $\mathrm{MR}$ & $\mathrm{MR}$ & $\mathrm{R}$ & $\mathrm{MR}$ & $\mathrm{MR}$ & $\mathrm{MR}$ & $\mathrm{R}$ \\
$\mathrm{Gi}$ & $\mathrm{MR}$ & $\mathrm{R}$ & $\mathrm{S}$ & $\mathrm{MR}$ & $\mathrm{R}$ & $\mathrm{R}$ & $\mathrm{R}$ & $\mathrm{R}$ & $\mathrm{R}$ \\
$\mathrm{Ki}$ & $\mathrm{S}$ & $\mathrm{R}$ & $\mathrm{MR}$ & $\mathrm{R}$ & $\mathrm{R}$ & $\mathrm{MR}$ & $\mathrm{MR}$ & $\mathrm{S}$ & $\mathrm{R}$ \\
\hline
\end{tabular}

$† \mathrm{Pi}=$ Pokhara, $\mathrm{Ri}=$ Rampur, $\mathrm{Ki}=$ Kabre, Li=Lumle and $\mathrm{Gi}=$ Gulmi isolates of Pyricularia Grisea

Isolates from Lumle could not develop susceptible reaction in any tested lines. It developed moderately susceptible reaction in 5 lines (ACC\#6202, HR\#911, KABRE, ACC\#456, PR\#202, KLB\#184) while developed resistance reaction in three lines as no clear cut differential reaction which could be used to identify the resistance gene. However, it could be generalized that the lines GPU\#48 and SPFMK\#2 might have the major genes governing blast resistance while other lines might have minor genes for resistance. However, to elaborate the clear cut interaction in finger millet blast interaction, a set of differential varieties is necessary. 
Table 3. Average disease score of selected finger millet lines tested with five different isolates in screen house, Rampur, Chitwan, 2008

\begin{tabular}{l|l|l|l|l|l|l|l|l|l}
\hline Isolate/Lines & ACC4337 & ACC6202 & HR911 & KABRE & SPFMK2 & ACC456 & PR202 & KLB184 & GPU48 \\
\hline $\mathbf{P i}$ & 5 & 6 & 6 & 2 & 2 & 2 & 3 & 2 & 2 \\
$\mathbf{R i}$ & 4 & 5 & 2 & 2 & 2 & 2 & 3 & 2 & 2 \\
$\mathbf{L i}$ & 2 & 3 & 3 & 4 & 1 & 4 & 4 & 4 & 2 \\
$\mathbf{G i}$ & 3 & 1 & 5 & 4 & 1 & 1 & 1 & 2 & 1 \\
$\mathbf{K i}$ & 5 & 1 & 3 & 1 & 2 & 3 & 3 & 5 & 1 \\
\hline
\end{tabular}

Sreenivasaprasad et. al. (2000) reported that in general, $P$. grisea isolates were relatively more or less aggressive on all the finger millet varieties tested, and no clear cut differences in compatibility were observed among the various fungus isolates and the finger millet varieties. This suggests that there was no gene-forgene relationship between these finger millet and the pathogens necessary as in rice blast, implying no major genes for resistance were involved in these interactions.

Hence, it is needed to develop a set of finger millet differentials for successfully assess the racial differentiation in the pathogen population prevailing in a particular geographical region.

\section{Acknowledgements}

Thanks are due to Hill Crop Research Programme, Kabre (Dolakha) and Global Future Institute (GFI) for providing fund to this work. The assistance from Ram Chandrika Prasad, Coordinator of National Hill Crop Research Programme, Kabre, Dolakha, Dev Narayan Tiwari, Regional Agricultural Research Station, Lumle, Madhav Lamsal, Regional Agricultural Directorate, (Dipayal), Doti, Dhan Raj Gautam (Jumla), Sunita Adhikari (Pokhara) and Nawaraj Bhandari (Gulmi) are appreciated for their help during disease sample collection. Thanks are due to Dhundi Raj Sharma, Nepal Agriculture Research Council, Agricultural Botany Division; Khumaltar for providing finger millet lines without which the research was impossible.

\section{References}

Akai, S. 1939. On the ash figures of the leaves of the rice plants transplanted from the different kinds of nursery beds and their susceptibilities to the blast disease, Annual Phytopathological Society Japan 9:223-235.
Atkins, J. G., A. L. Robert, C. R. Adair, K. Goto, T. Kozaka, R. Yanada and S. Matasumoto. 1967. An international set of rice lines for differentiating races of Pyricularia oryzae. Phytopathology 57: 297-301.

Barman, J. M. 1990. Host plant resistance for rice plant management in the tropics third international conference on plant protection on tropics: Magnaporthe grisea from India thatare pathogenic to finger millet and to rice. Mycological Research 104:161-167. Euphytica 63: 271-279.

Bonman, J. M., T. I. Vergel de Dios, M. M. Khin.1986. Physiologic specialization of Pyricularia oryzae in the Phillipines. Plant Disease 70: 767-769.

CGIAR. 2007. Finger millet,www.cgiar.org \impact $\backslash$ millet html, retrieved at $20^{\text {th }}$ April , 2007.

Chen, D., R. S. Zeigler, H. Leung, and R. J. Nelson.1995. Population structure of Pyricularia grisea at two screening sites in the Philippines. Phytopathology 85 : 1011-1020.

Conroy, M. A. and M. Julion, 1999. An investigation into biology, epidemiology and management of finger millet blast in low input farming system of east Africa. Final Technical Report for Natural Resources Institute, University of Greenwich.

Ghimire, S.R. and P.M. Pradhnang.1994. Plant disease monitoring and disease pest diagnosis 1992193. Working papers no 94/26. Lumle Agricultural Research Center.

Glatgong, P and R. A Frederitson. 1969. Pathogenic variability and cytology of monoconidial subculture of Pyricularia oryzae. Phytopatholgy 59:1152-1157.

Gomez, K. A., and A. A. Gomez. 1994. Statistical procedures for agricultural research.(2nd ed.). USA, New York: Wiley.

HCRP. 2003. Finger millet research report. Annual report 1997. NARC\HCRP, Kabre, Dolakha

HCRP. 2007. Finger millet research report. Annual Report 2007. NARC \HCRP, Kabre, Dolakha.

Hunsigi, G. and K.R.Krishna. 1998. Science of field crop production; Finger millet, New Delhi Oxford and IBH publishing Co Pvt. ltd., pp 132.

ICRISAT, 2007. Finger millet (Eleusine coracana (L.)). www.icrisat.org $\backslash$ millet, retrieved on 20 $0^{\text {th }}$ April, 2009. 
Kahn, R. P. and J. L. Libby. 1958. The effect of environmental factors and plant age on the infection of rice by the blast fungus Pyricularia oryzae. Phytopathology 48: 25-30.

Karthikeyan, V., S. S. Gnanamanickam, A. C. Amadioha. 2000. Biological control of Setaria blast (Magnaporthe grisea) with bacterial strains controlling rice blast in vitro and in vivo with extracts of Azadirachta indica. Crop Protection 19: 287-290.

Kato, H. 1978. Biological and genetic aspects in the perfect state of rice blast fungus Pyricularia oryzae cav and its allied, In: Mutation breeding in disease resistance report of symposium held on July, 20-21, 1978, Institute of radiation breeding Nias Maff, Ohmiya, Naka, Ibaraki, Japan.

Koh, Y. J., B. K. Hwang, H. S. Chung.1987. Adult-plant resistance of rice to leaf blast. Phytopathology 77:232236

Kumar, J., R. J. Nelson and R. S. Zeigler. 1999. Population Structure and Dynamics of Magnaporthe grisea in the Indian Himalayas. Retrieved from http:// www.genetics.org/content/152/3/971.full.pdf at 10 Dec. 2010.

Latha, A. M., K. V. Rao, and V. D. Reddy. 2005. Production of transgenic plants resistant to leaf blast disease in finger millet (Eleusine coracana (L.) Gaertn.), Plant Science 169: 657-667.

Ling, K. C., S. H. Ou.1969. Standardization of the international race number of Pyricularia oryzae. Phytopathology 59: 339-342.

Levy, M. J, M. Ramao, M. A. Marchetti, and J. E. Hamer. 1991. DNA fingerprinting with a disopersed repeated sequence resolves pathotype in rice blast fungus. Plant cell 3:95-102.

Levy, M., F. J. Correa, R. S. Zeigler, S. Xu, and J. E. Hamer.1993. Genetic diversity of the rice blast fungus in a disease nursery in Columbia. Phytopathology 83: 1427-1433.

Mekwatanakarn, P., W. Kositratana, M. Levy and R. S. Zeigler. 2000. Pathotype and avirulence gene diversity of Pyricularia grisea in Thailand as determined by rice lines near-isogenic for major resistance genes. Plant Disease 84:60-70.

Nakayama, H., T. Nagamine and N. Hayashi. 2005. Genetic resources and crop evolution genetic variation of blast resistance in foxtail millet (Setaria italica (L.) P. Beauv.) and its geographic distribution. Genetic Resources and Crop Evolution 52: 863-868.

NARC. 1997. Finger millet research report, In: Annual Report 1997. NARC $\backslash$ NARI, Khumaltar, Lalitpur, Nepal.
Ou, S.H. 1972. Rice diseases. Commonwealth Mycological Institute. Kew, Surrey, England.

Ou, S. H. 1979. Breeding rice for resistance to blast: A critical view. In: Proceeding of Rice Blast Workshop, International Rice Research Institute, Manila, pp.79137.

Park, S.Y., M. G. Milgroom, S. S. Han, S. Kang, and Y.H. Lee. 2003. Diversity of pathotypes and DNA fingerprint haplotypes in populations of Magnaporthe grisea in Korea over two decades. Phytopathology 93 (11): 1378-1385.

Prasad, R.C. 2008. Annual research report. Finger millet research report, 2006, Hill crop Research Programme, Kabre, Dolakha.

Roumen, E. C. 1992. Leaf age related partial resistance to Pyricularia oryzae in tropical lowland rice cultivars as measured by the number of sporulating lesions. Phytopathology 82: 1414-1417.

Shrestha, S. M. and N. K. Mishra. 1994. Evaluation of common cultivars of rice against leaf and neck blast in Nepal. Journal of Institute of Agriculture and Animal Science 15:101-103.

Sreenivasaprasad, S., J. Chipili, and S. Muthumeenakshi. 2001. Diversity and dynamics of phytopathogenic fungi: Application of molecular tools. In: Proceedings of the 11th Mediterranean Phytopathological Congress, University of Evora, Portugal. 17-20 September. 2001. pp.21-22.

Sreenivasaprasad, S., J. Chipili, and Y. Sere. 2000. Diversity and distribution of blast pathogen Magnaporthe grisea lineages at some rice screening sites in West Africa. In: Proceedings of the Rice in Africa, NRI Workshop, Chatham, December 6-8, 1998.

Sreenivasaprasad, S., J.P. Takan, A.B. Obilana, E. Manyasa, A. E. B. Brown, R. Bandyopadhyaya, and S. Muthumeenakshi, 2004. Finger millet blast in East Africa: Pathogen diversity and disease management strategies R8030 (ZA0482) final technical report 1 April 2001 - 30 November 2004 Dec, Crop protection programme.

Subedi, M. and C. B. Budhathoki. 1996. Evaluation of finger millet lines for maizelmillet system and examination of the source- sink relationship in finger millet. LARC working paper no 96/31.Lumle Agriculture Research Center.

Zeiglar, R.S. 1998. Recombination in M. grisea. Annual review of phytopathology 36:249-275.

Zeigler, R. S., R. P. Scott, H. Leung, A. A. Bordeos, J. Kumar and R. J. Nelson. 1997. Evidence of parasexual exchange of DNA in rice blast fungus challenges its exclusive clonality. Phytopathology 87: 284-294. 
Nepal Journal of Science and Technology Vol. 14, No. 2 (2013) 17-24 